Bull. Fac. Agric., Cairo Univ.,69:243-253 (2018).

\title{
DESIGNING AN INDEX FOR CRITERIA OF THE MANAGEMENT QUALITY ASSURANCE IN AGRICULTURAL EXTENSION IN EGYPT (MANQUALEX)
}

(Received:29.11.2018)

\author{
By \\ A.M.Diab \\ Department of Rural Sociology and Agricultural Extension, Faculty of Agriculture, \\ The New Valley University, Egypt
}

\begin{abstract}
The purpose of this study is to design and validate an index for the criteria of management quality assurance of the agricultural extension organization of Egypt (MANQUALEX), to be used in the case of implementing quality assurance standards in agricultural extension. By reviewing the available relevant literature concerning quality assurance in service organizations, four key dimensions could be considered as essential components of the proposed scale as follows: 1) Customer focus; 2) Continuance improvement in agricultural extension; 3) Training and empowering the extension personnel; and 4) Evidence-based decision making. In order to achieve the objective, central level extension employees were selected to be the sample of the study where the sample size reached 32 respondents representing $58.2 \%$ of the total central level extension employees (55 employees). The data were collected during March and April 2016 through personal interviews using questionnaire form. Percentages, average, standard deviation, Pearson's correlation coefficient, and reliability and validity analysis tests were used for data analysis and presentation. Reliability coefficient (Cronbach's Alpha) was about 0.909 , internal validity coefficient was 0.953 and statistical validity coefficient 0.984. By testing the internal validation using Pearson's correlation coefficient, the final version of the scale contains 66 statements divided represent the four components of the scale, 25 for customer focus, 10 for continuance improvement in agricultural extension, 17 for training and empowering the extension personnel, and 14 for evidence-based decision making
\end{abstract}

Key Words: Quality assurance, quality management, agricultural extension, Egypt.

بناء مقياس لمعايير ضمان جودة الإدارة في الإرشاد الزراعي في مصر (MANQUALEX)

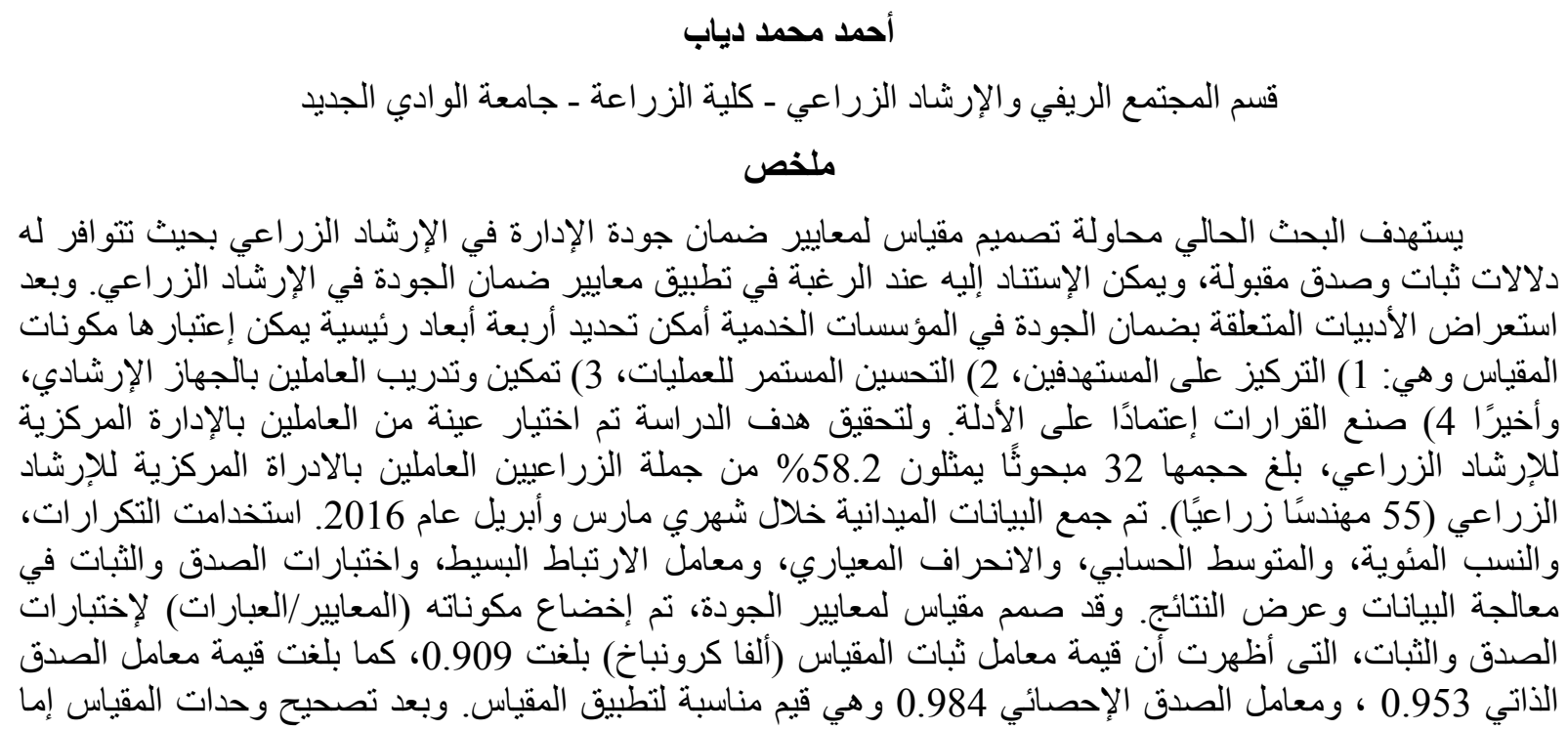




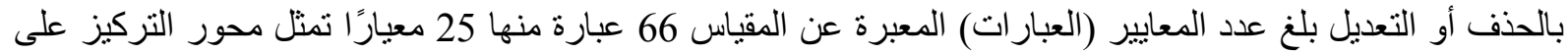

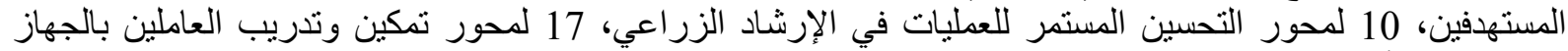

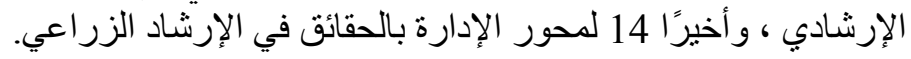

الإرشاد الزراعي على الإنتاجية و الدخل المزرعي والإدارة

المستدامة للموارد الطبيعية (Swanson, 2009).

ولقد أصبحت الجودة إحدى ألدئ (أدوات تحقيق كفاءة

العمليات وأداء الأعمال في كل من الجئ القطاعين الإنتاجي

والخدمي على حد سواء بماء في في ذلاء فلك جهاز الإرشاد الإنتاد

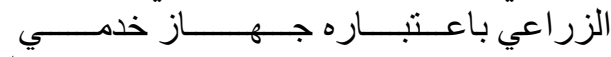

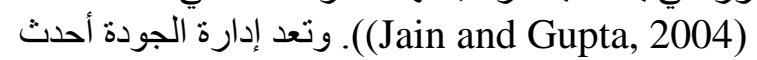

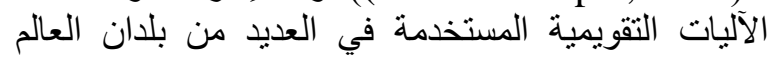

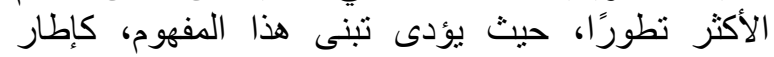

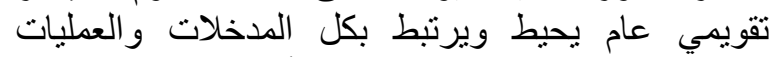

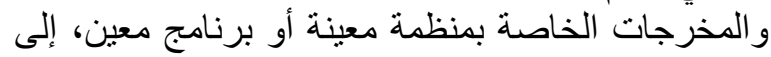

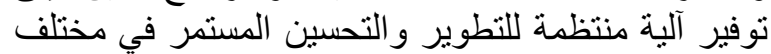

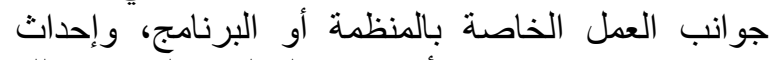

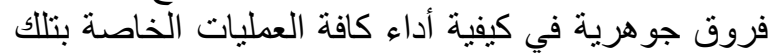

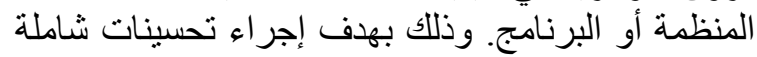

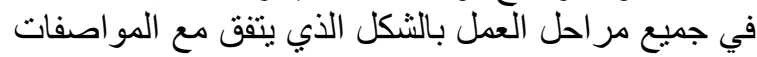

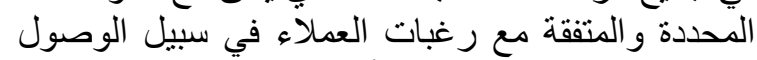
ليس فقط إلى إرضاء العملاء أو إسعادهم و إنما إلى إبهار هم العهم

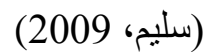

وتشتمل جهود تحسين الجودة في المنظمات على (2009

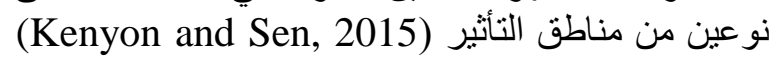
أولها: جودة الإدارة والتي نتكون من جودة سلسلة الإمداد Supply Chain وجودة الإدارة ولني

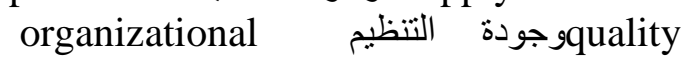
وuality

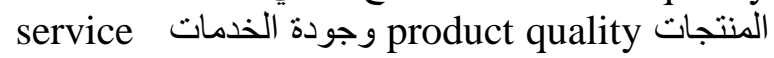

وكلمة إدارة لا تعني أن هذه العملية خاصة

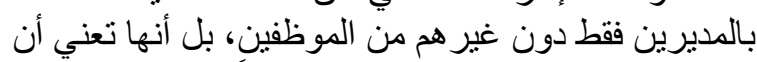

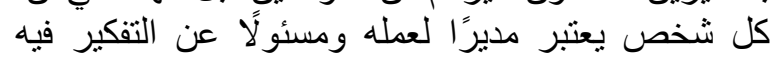

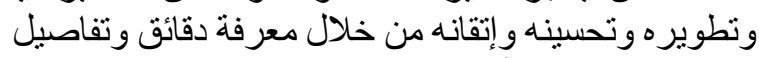
ذلك العمل، فلابد أن تشمل هذه الإنه الإدارة جميع العاملين

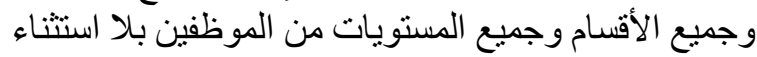

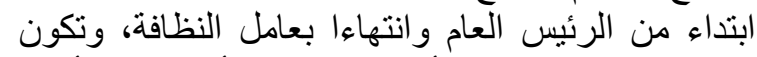

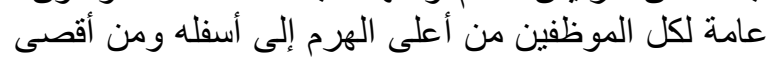

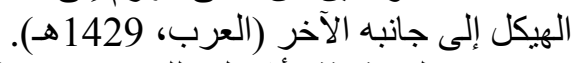
وهنالك ثلاثة أشكال للجودة في النيان المنظمات هي

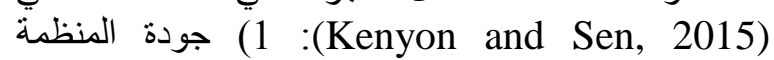
وهي الجودة المتعلقة ببيئة (organization's quality)

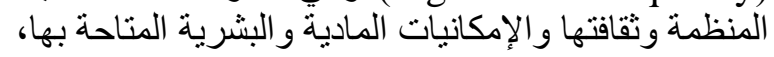

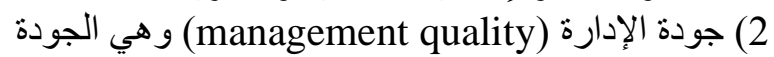

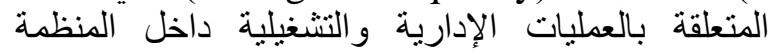

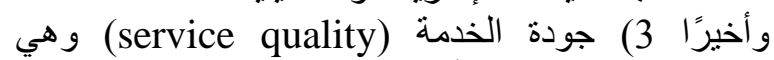
المتعلقة بجودة الخدمة أو المنتج النهائي الذي تقدمه هذه

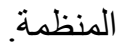

\section{1- 1 - 1المقدمة والهدف}

تتعدد الظروف المتغيرة للزفرة اعة والعهوف والعولمة و التوجه

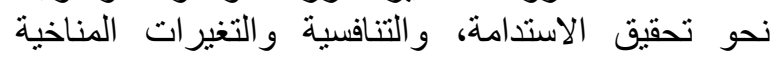

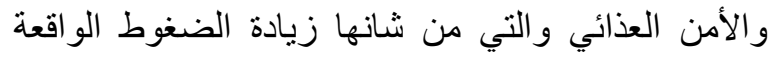

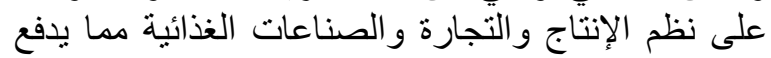

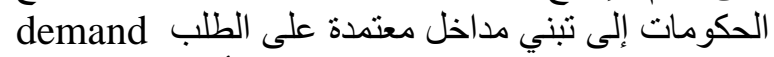
driven

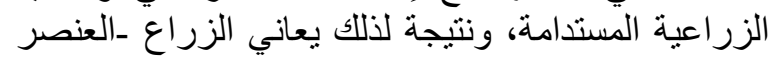

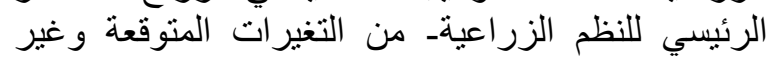
المتوقعةة في مهنة الزر اعنة

(Karbasioun et al, 2008)

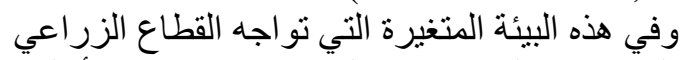

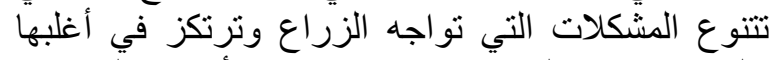

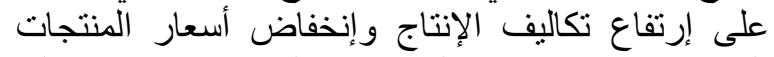

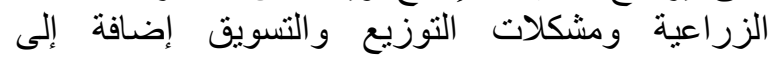

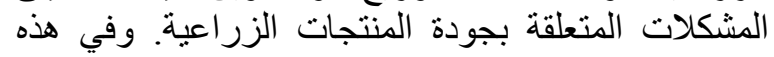

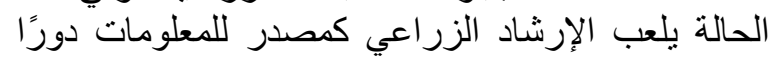

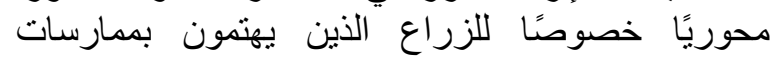

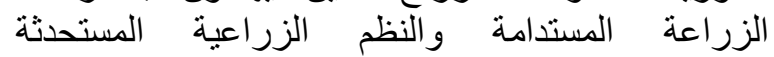

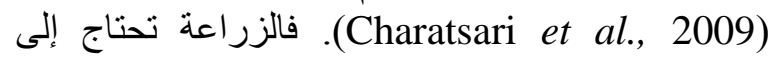

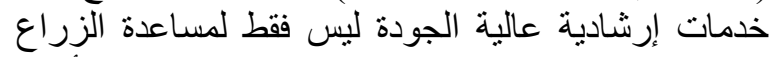
على التعاطي مع اللوائح الحكومية المعقدة، ولكن الجهن أيضًا

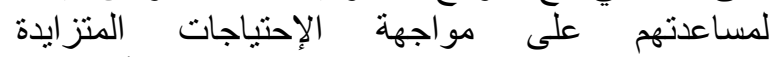

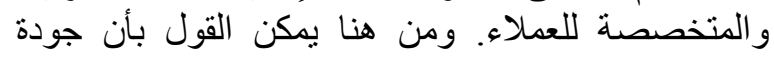

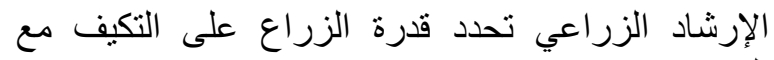
السوق (Schaafsma, and Mulder, 2009). هذا ينطلب اعتماد نظام إرشادي مبتكر يتميز ببعض الخصائص منها (Anandajayasekeram et al., 2008)

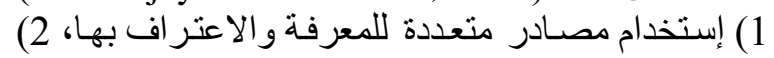



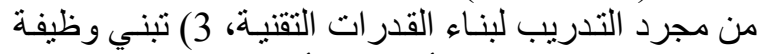

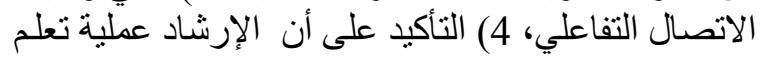
بالمشاركه و 5) ألتعددية المؤسية.

وتركز العديد من دول التعدية العزولية

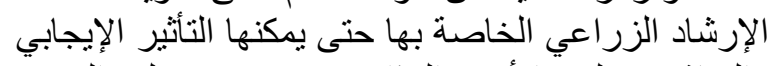

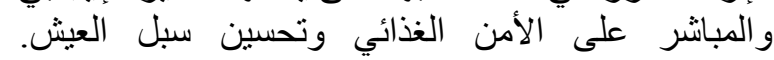

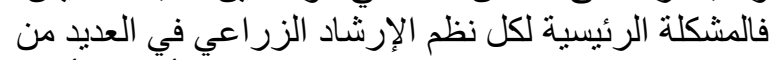

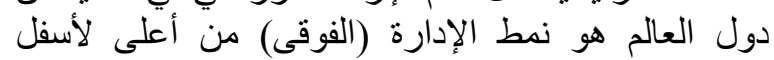

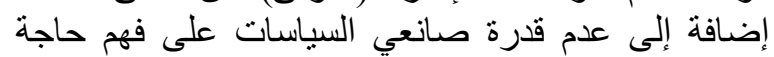

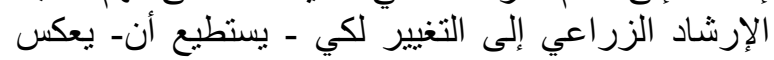

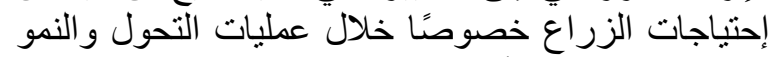

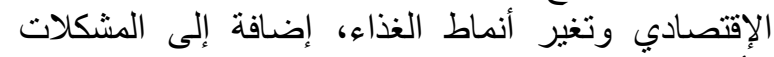

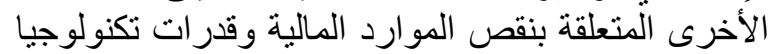

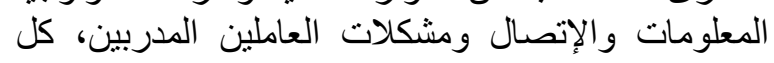

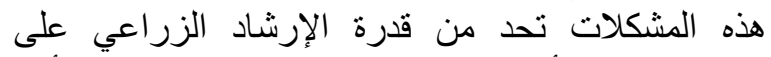
الإستجابة إلى الأولويات القومية المتغيرة، مما يقلل من ألثر الزّر 
المنظمة للميزة التنافسية ونجاحها في تحقيق أهدافها، وهو

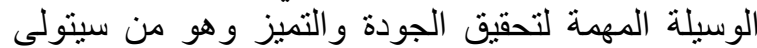

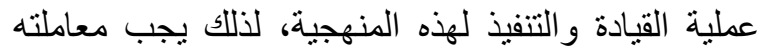

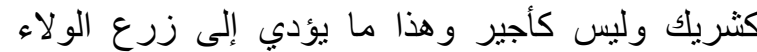

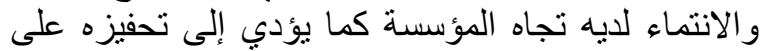

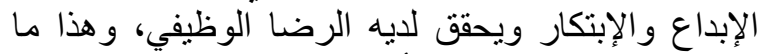

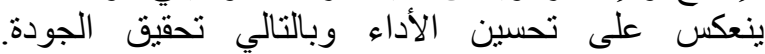

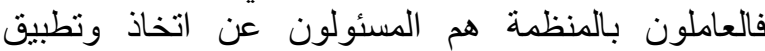



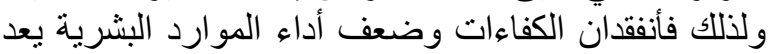

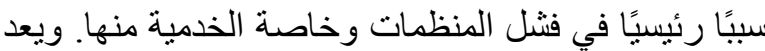

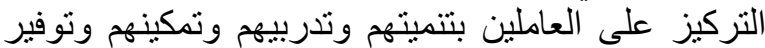

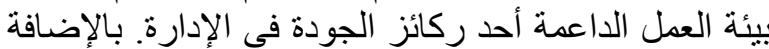

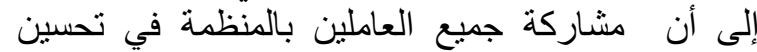

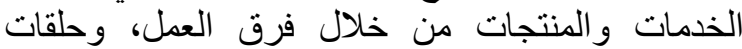

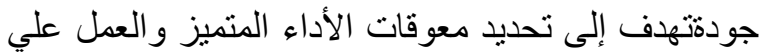

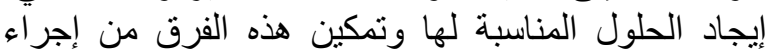

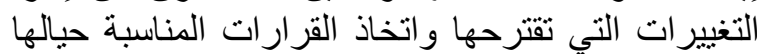

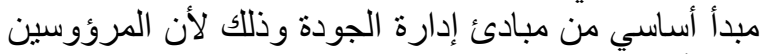

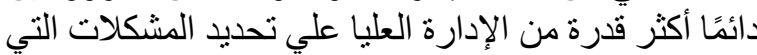

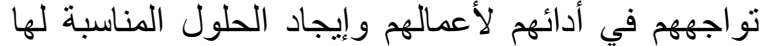

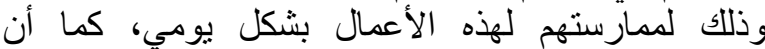

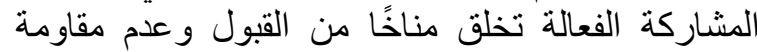

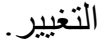

4.1.صنع القرارات إعتمادًا على الأدلة: تشكل المعلومات

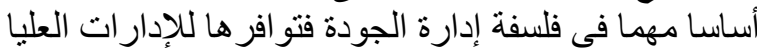

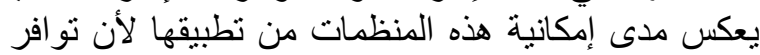

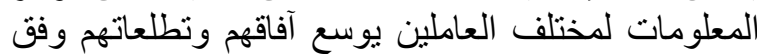

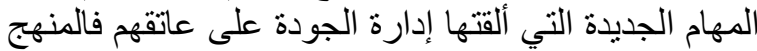

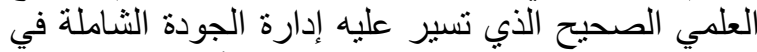
حل المشاكل يكون ذا فائدة كبيرة لها لأنه يمثل إمكانية

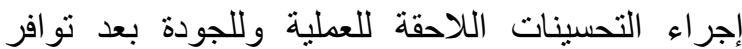

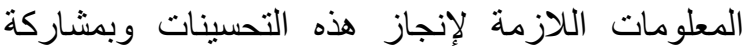
العاملين بما يجعل نشاط المنظمة فعالًا ومؤثرًا. فالقر ارات اترات

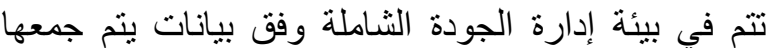

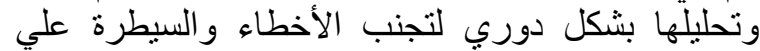

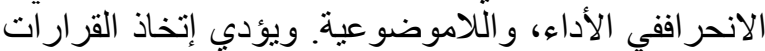

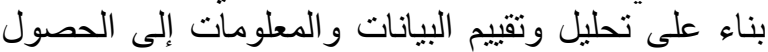

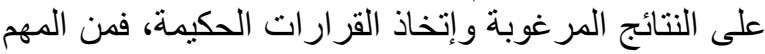

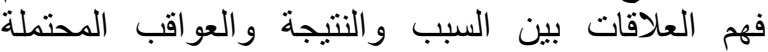
للقرارات. فيؤدي إستخدام الحقائق و الدلائل وتحليل البئي البيانات

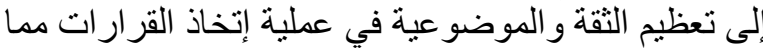

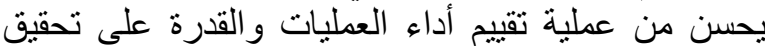
هداف المنظمة.

ويفترض في الجهاز الإرشادي أن يستجيب إلى إلى إلى إلى

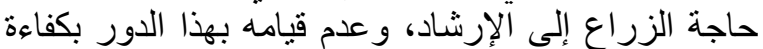

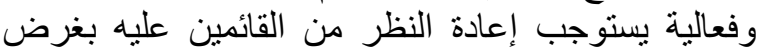

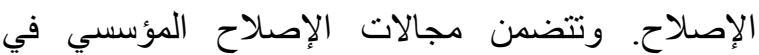

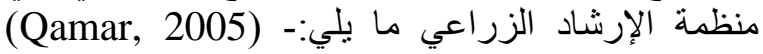
1)تغييرات إصلاحية في الهيكل التنظيمي القائد
وتعتمد إدارة الجودة على مبدأ أن العاملين يقومون

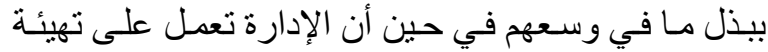

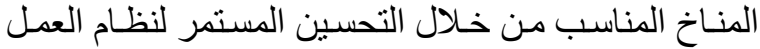
و العمليات الإداريـة (Farooq et al., 2007). وتركز الإنيان فلسفة جودة الإدارة بشكل أساسي على تطويل الإدير وتنفيذ بيئة

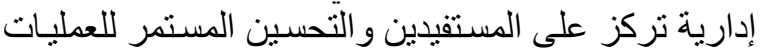

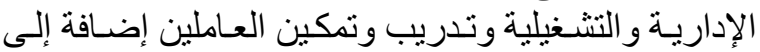

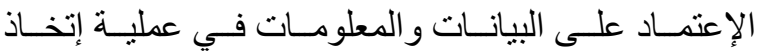
القرارات (Kenyon and Sen, 2015). وللجودة العديد من المبادئ، و الإدة تختلف الأهمية النسبية لكل مبدأ من مبادئ جودة الإدارة من منظمة العندة لأخرى كما بمكن أن تتغير تلادئ المبادئ بمرور الإدارة من الوقي،

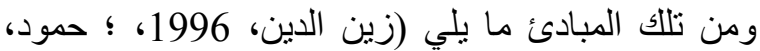

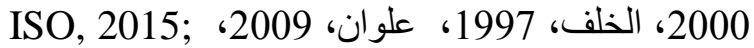
.(Kenyon and Sen, 2015 1.1.التركيز على المستهدفين: الهدف الأساسي للجودة هو مقابلة إحتياجات العملاء أو المستفيدين ومحاولة المينة تحقيق لإنيق

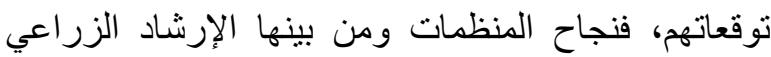

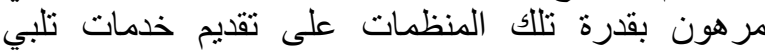
إحتياجات المستهدفين. حيث تضع الجودة الجنات العمبل في مقدمة

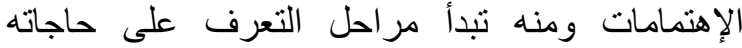
ورغباته، ومن ثم ترجمنها في عمليات الات تصميم المنتج

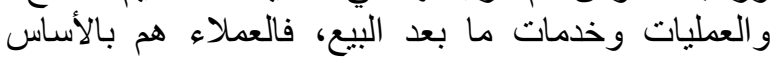

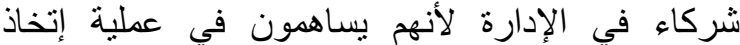

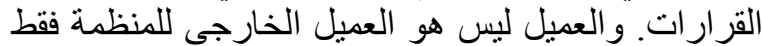

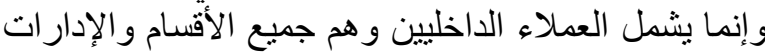

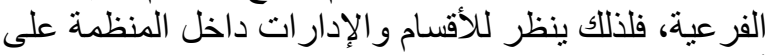

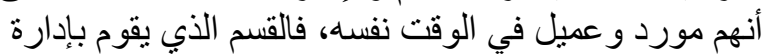

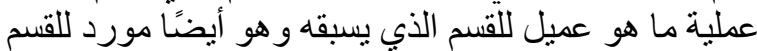

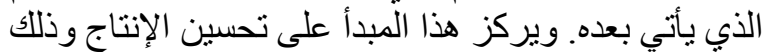

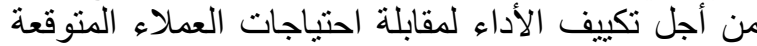

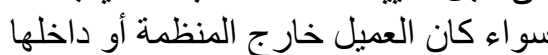

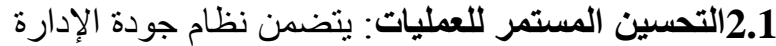
التحسين المستمر للعمليات والذي يؤيني لأدي إلى تعظيم أداء

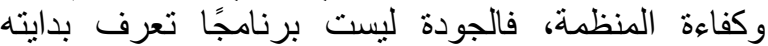

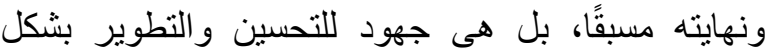

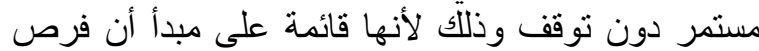

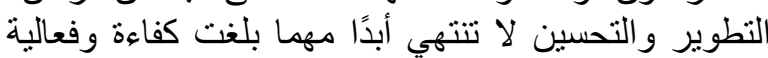

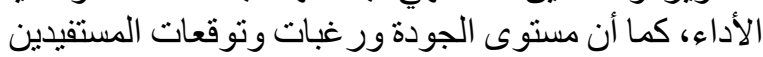

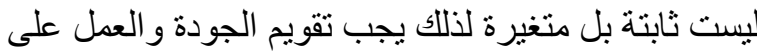

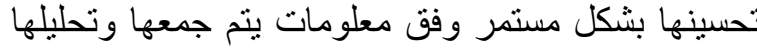
بشكل دوري، وذلك لجعل كل مظهر من مظاهر العمليات

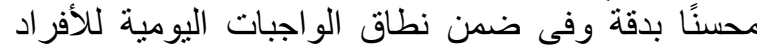

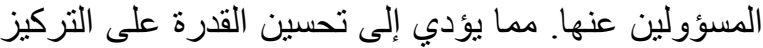

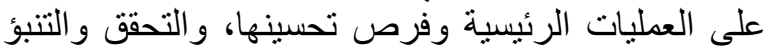

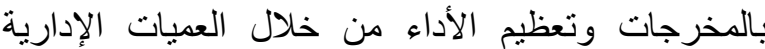

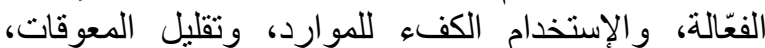

إضافة إلى التركيز المستمر على تحسين مستويات الإنى الأداء.

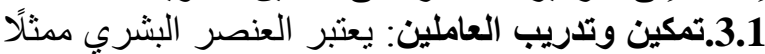
في العاملين بالمنظمة أحد أهم العوامل المسئولة المنئ عن إمتلاك 


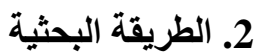

1.2. منهج الدراسة

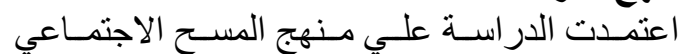

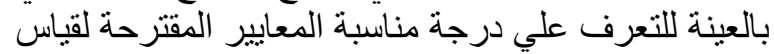

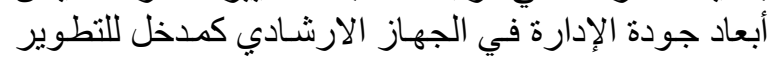

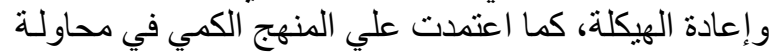

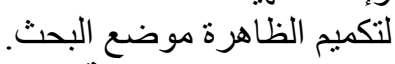

1.2.2. المفاهيم الإجرائية الئية

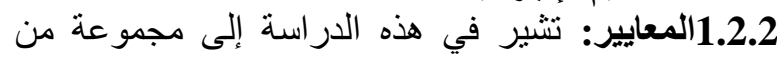

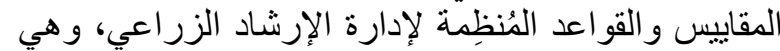

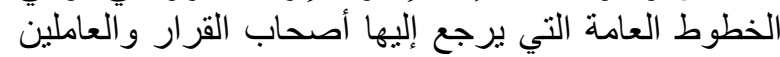
في الإرشاد الزراعي للحكم على الجودة الإدارية بالإرشاد. الإلئ

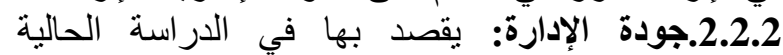

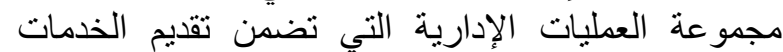

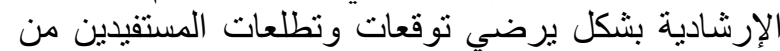

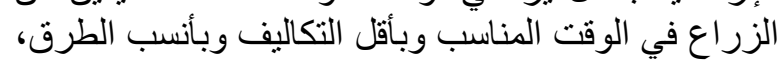

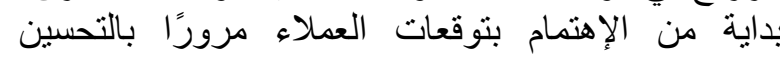

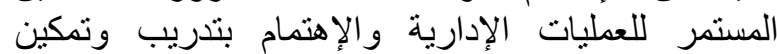

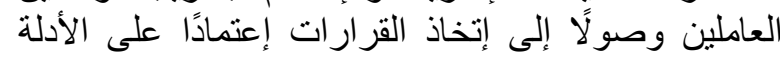

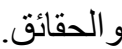

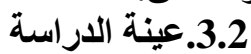

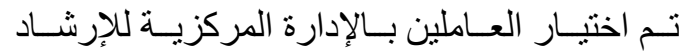

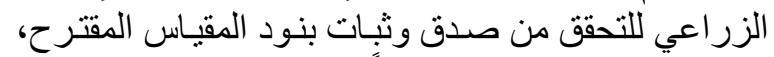

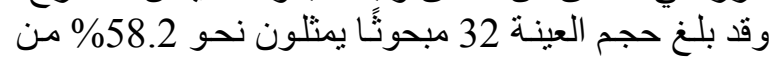

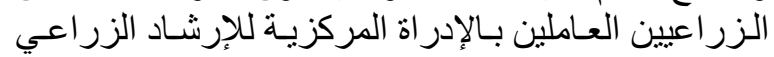

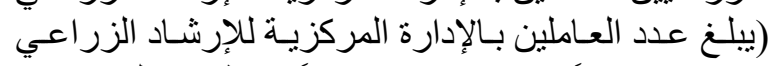

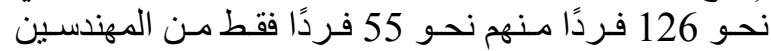

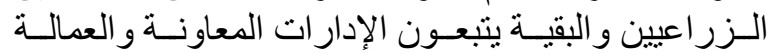

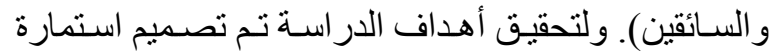

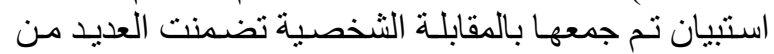

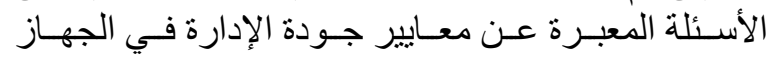

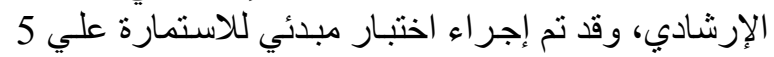

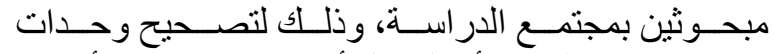

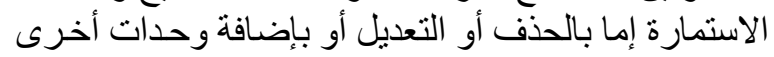

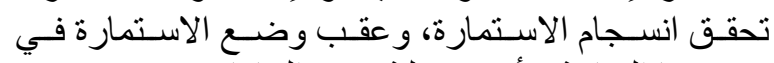

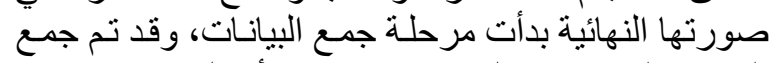
البيانات الميدانية خلال شهري مارس درس وأبريل 2016. 4.2.أدوات التحليل الإحصائي

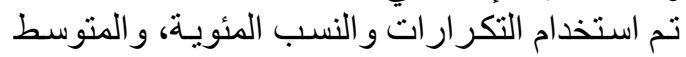

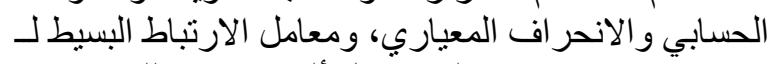

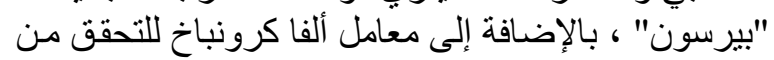
ثبات وصدق وصلاحية المقياس.

3. إعداد المعاييز

في ضوء معايير جودة الإدارة في الإرشاد المادير الزراعي

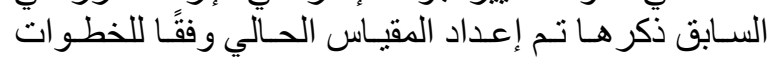

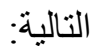

1.3.إعداد الصورة الأولية للمعايير

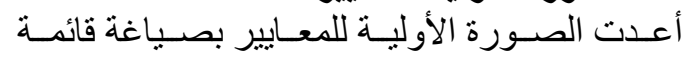

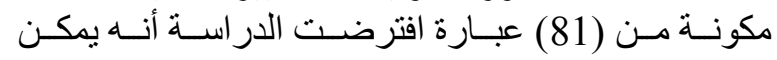

2) تعديلات في الروابط التشغيلية مع المؤسسات المعنية

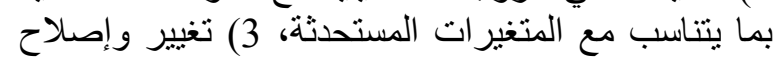

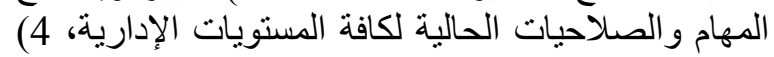

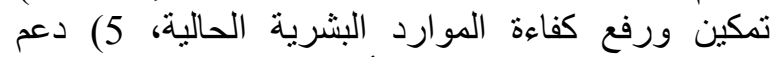

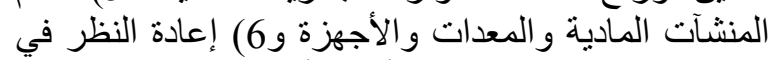

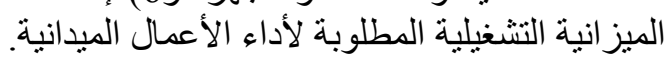

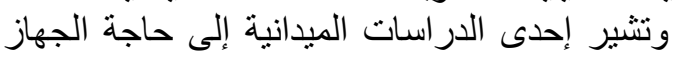

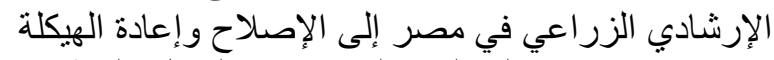

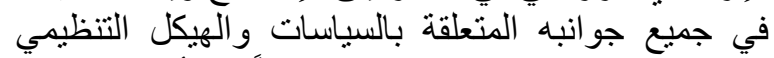

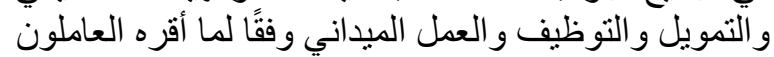

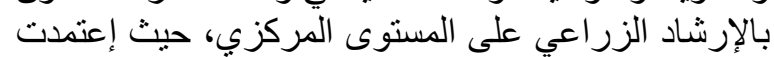

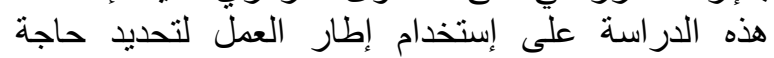

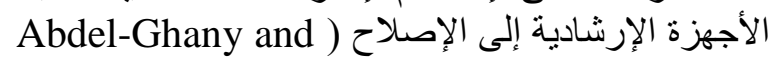

.(Diab, 2013

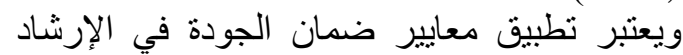

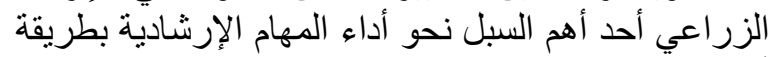

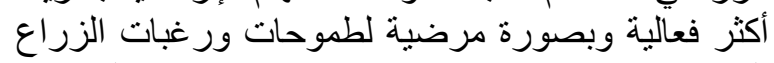

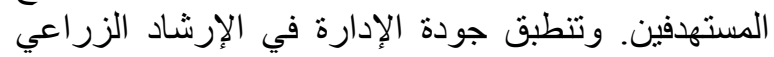

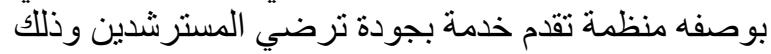

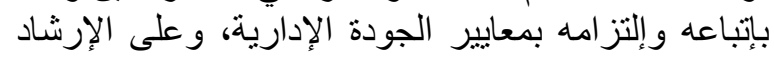

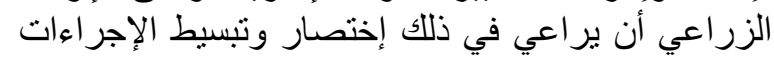

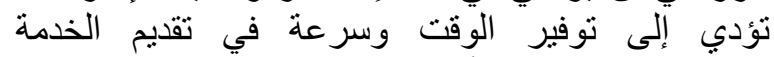

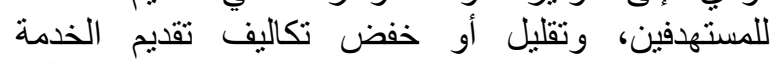

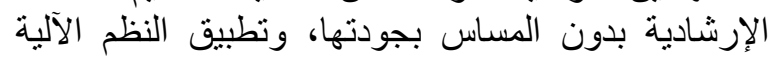

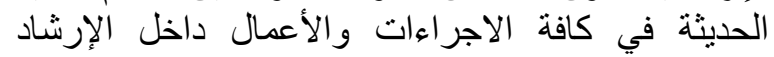
الزراعي، وتطبيق النظم الإدارية وتحديثها مثل الهياكل الإنل

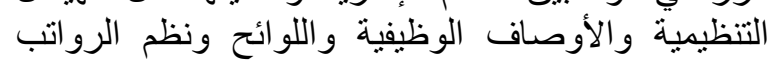

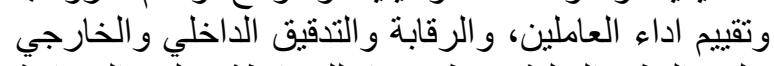

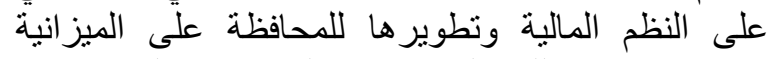

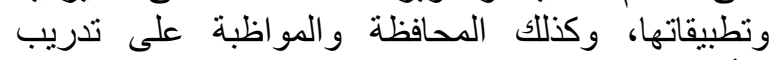
وتأهيل العاملين على مهار ات العمل العلى الحديثة.

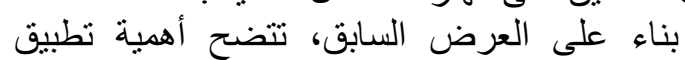

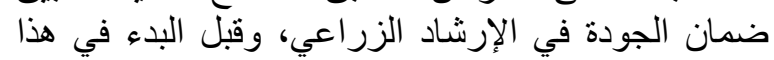

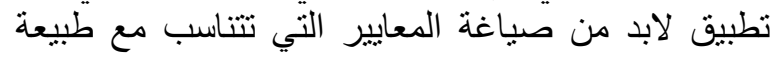

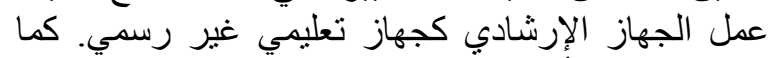

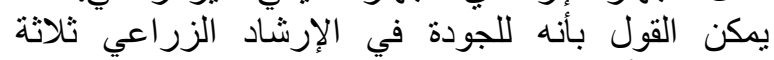

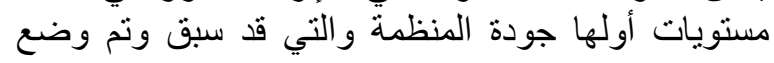

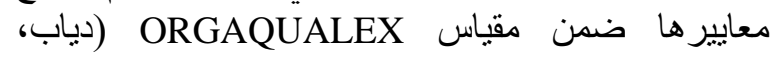
2017) وثنانيها جودة الإدارة (موضع إهنمان إنمام الدراسة الحالية) وثالثها جودة الخها الخدات التي يقدمها الإرشاد الثراد

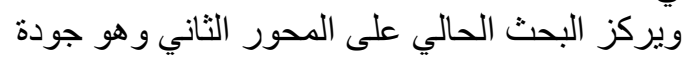

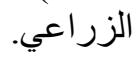

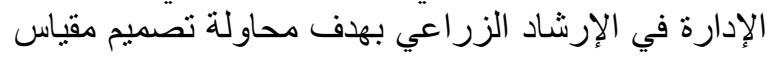

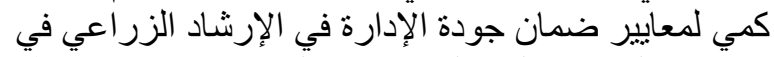

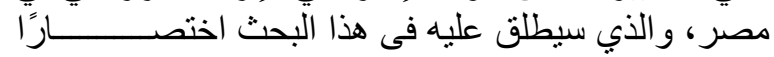

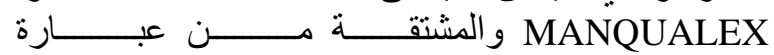
،MANagement QUALity in EXtension تتو افر له دلالات ثبات وصدق مقبولة، ويمكن إستخدامه

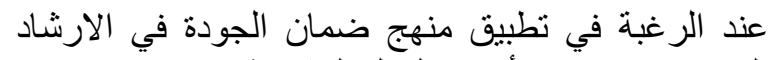
الزراعي في مصر أو في الدول المشابهة. 
و الدرجة الكلية للمقياس للتعرف على العبار ات ذات معامل

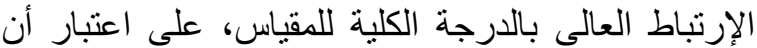

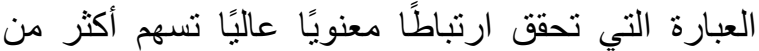
غير ها في قياس درجة جودة الإدارة بأبعادها الأربعة سالفة

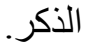

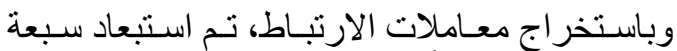

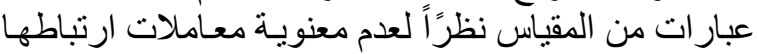

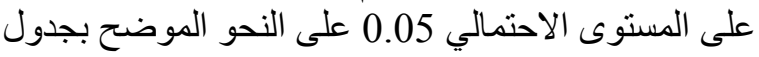

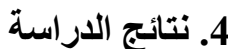

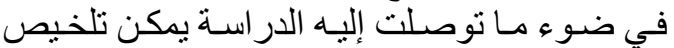

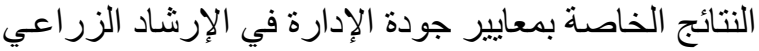
موضوع الدر اسة من خلال البنود التالية: 1.4. النتائج الخاصة بثبات وصدق النقال المقياس:



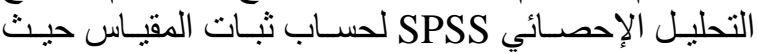

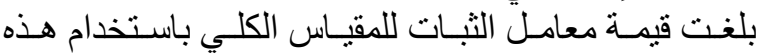

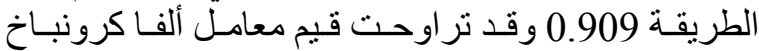

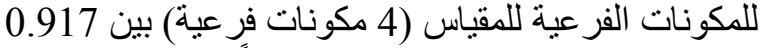

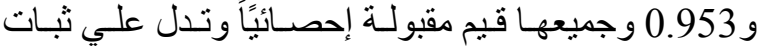

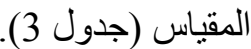

وبحسـاب معامـل الصـدق الذاتي (الجذر التربيعي

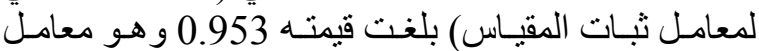

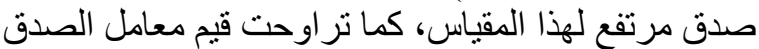

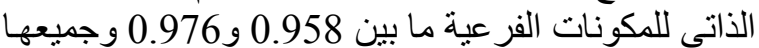

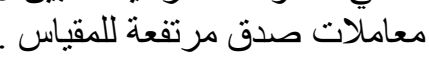

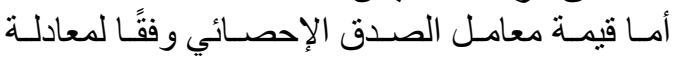

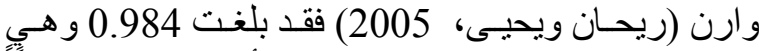

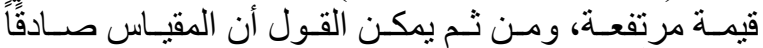

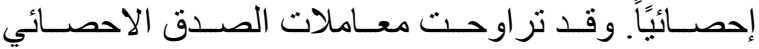

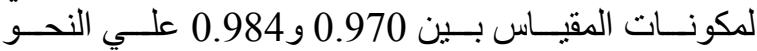

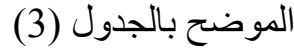
2.4. النتائج الخاصة بالاتساق الاخلي لمكونات المقياس

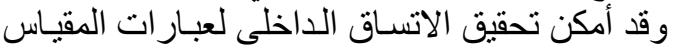
في هذه الدر اسة من خلال ثلاثثة محاور هي:

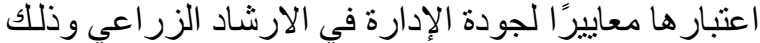

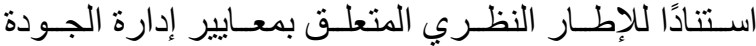

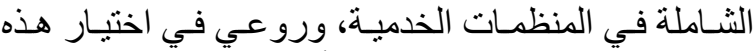

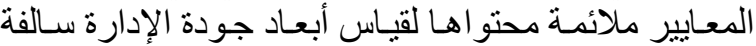

1.1.3.الصدق الظاهري للمقياس

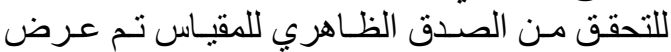

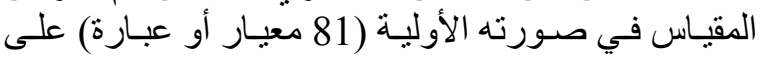



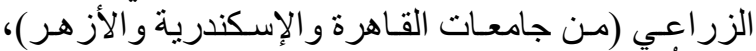

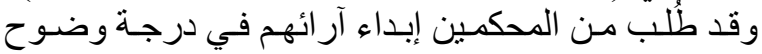

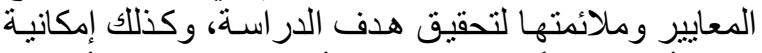

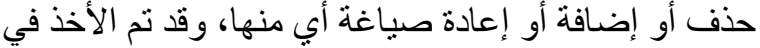
الاعتبار كافة الملاحظات التي وردت من المحكمين وكذلك التك اعتماد العبار ات التي حظيت بقبول جميت التيع المحكمين. وقد

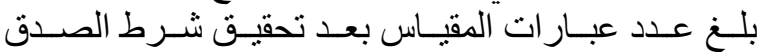

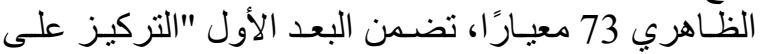

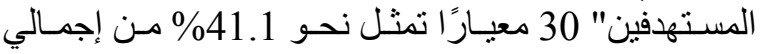

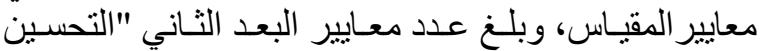

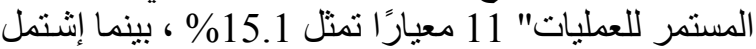

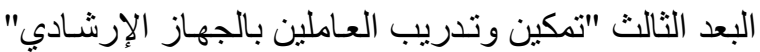

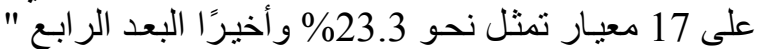

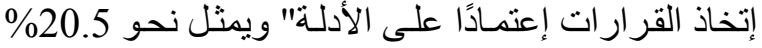

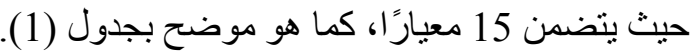
2.1.3. المرحلة التجريبية للمقياس: الترية

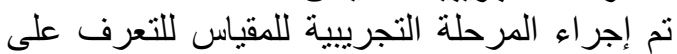

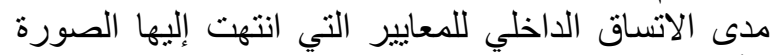

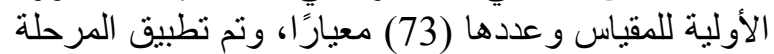

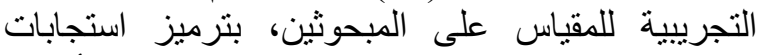

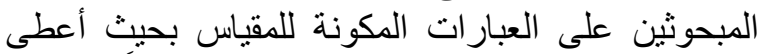

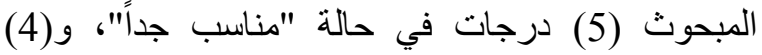

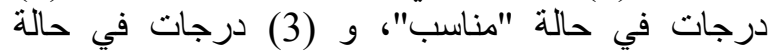

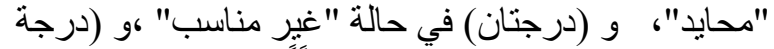

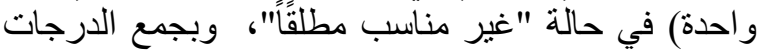

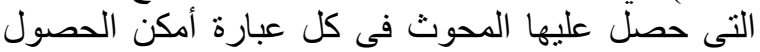

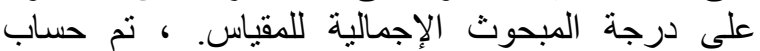
معاملات الارتباط البسيط "بيرسون" بين درجة كل عبارة

جدول (1): عدد ونسبة المعايير في كل بعد من أبعاد جودة الإدارة في الإرشاد الزراعي بصيغتها الأولية وبعد تحقيق الصدق الظاهزي لها.

\begin{tabular}{|c|c|c|c|c|}
\hline \multicolumn{2}{|c|}{ بعد تحقيق الصدق الظاهري } & \multicolumn{2}{|c|}{ الصورة الأولية } & \multirow{2}{*}{ أبعاد المقياس } \\
\hline$\%$ & عدد المعايير & $\%$ & عدد المعايير & \\
\hline 41.10 & 30 & 40.74 & 33 & البعد الأول: التركيز على المستهدفين \\
\hline 15.07 & 11 & 14.81 & 12 & البعد الثاني: التحسين المستمر للعمليات \\
\hline 23.29 & 17 & 22.22 & 18 & البعد الثالث: تمكين وتدريب العاملين بالجهاز الإرشادي \\
\hline 20.55 & 15 & 22.22 & 18 & البعد الر ابع: إتخاذ القرارات إعتمادًا على الأدلة \\
\hline 100 & 73 & 100 & 81 & المقياس الكلي \\
\hline
\end{tabular}

المصدر : بيانات الدراسة 
جدول (2) : معاملات ارتباط الوحدات الأولية لمعايير جودة الإدارة في الجهاز الارشادي مع الدرجة الكلية للمقياس.

\begin{tabular}{|c|c|c|c|c|c|c|c|c|}
\hline الارتباط & المعيار & الارتباط & المعيار & الارتباط & المعيار & الارتباط & المعيار & أبعاد المقياس \\
\hline${ }^{* *} 0.701$ & 4 & ${ }^{* *} 0.851$ & 3 & 0.830 & 2 & 0.590 & 1 & \multirow{8}{*}{ البعته الأول: التركيز على } \\
\hline 0.705 & 8 & ${ }^{*} 0.851$ & 7 & 0.767 & 6 & ${ }^{*} 0.851$ & 5 & \\
\hline 0.139 & 12 & 0.257 & 11 & 0.618 & 10 & 0.415 & 9 & \\
\hline 0.830 & 16 & 0.493 & 15 & 0.009 & 14 & 0.175 & 13 & \\
\hline 0.617 & 20 & ${ }^{*} 0.620$ & 19 & 0.533 & 18 & 0.874 & 17 & \\
\hline 0.854 & 24 & 0.653 & 23 & 0.737 & 22 & 0.594 & 21 & \\
\hline 0.653 & 28 & 0.751 & 27 & 0.766 & 26 & 0.702 & 25 & \\
\hline$x x$ & $x \times$ & $x x$ & $x \times$ & 0.235 & 30 & 0.712 & 29 & \\
\hline 0.237 & 34 & 0.519 & 33 & 0.635 & 32 & 0.585 & 31 & \multirow{3}{*}{ العمليات الثاني: التحسين المستمر } \\
\hline ** 0.834 & 38 & 0.462 & 37 & 0.504 & 36 & ${ }^{*} 0.825$ & 35 & \\
\hline$x \times$ & $x \times$ & * 0.872 & 41 & 0.907 & 40 & ${ }^{*} 0.883$ & 39 & \\
\hline 0.728 & 45 & 0.743 & 44 & 0.728 & 43 & ${ }^{*} 0.860$ & 42 & \multirow{5}{*}{ العاملين الثالثهاز الإرشين وتدريب } \\
\hline 0.854 & 49 & 0.562 & 48 & 0.512 & 47 & 0.664 & 46 & \\
\hline 0.653 & 53 & *0.751 & 52 & 0.766 & 51 & ${ }^{*} 0.702$ & 50 & \\
\hline 0.926 & 57 & 0.865 & 56 & 0.571 & 55 & 0.910 & 54 & \\
\hline$x x$ & $x x$ & $x x$ & $x x$ & $x x$ & $x x$ & 0.629 & 58 & \\
\hline 0.230 & 62 & ${ }^{*} 0.544$ & 61 & 0.710 & 60 & 0.637 & 59 & \multirow{4}{*}{ لبمادًا على الإدلة: إتخاذ القرارات } \\
\hline 0.634 & 66 & 0.677 & 65 & 0.748 & 64 & 0.600 & 63 & \\
\hline *0.571 & 70 & 0.514 & 69 & *0.653 & 68 & 0.513 & 67 & \\
\hline$x x$ & $x x$ & 0.642 & 73 & 0.926 & 72 & 0.865 & 71 & \\
\hline
\end{tabular}

جدول ( 3 ): نتائج التحليل الإحصائي للوحدات (المعايير) التي استوفت شروط تكوين مقياس معايير جودة الإدارة في الجهاز

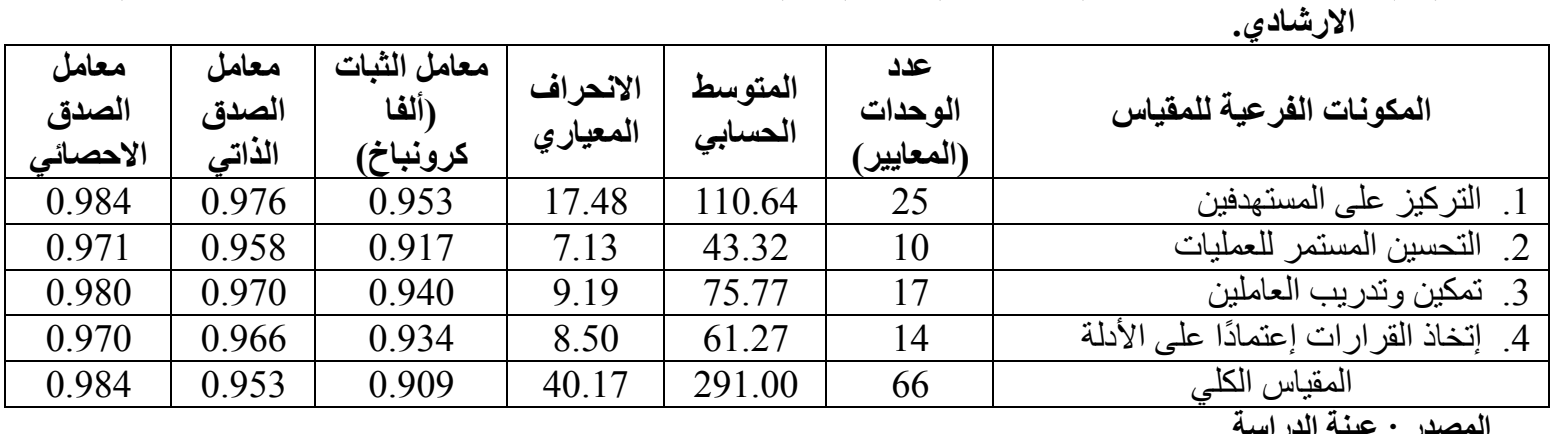

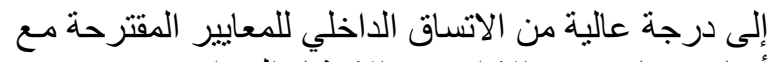

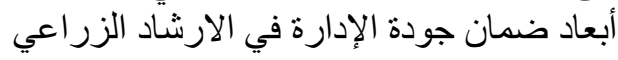

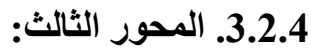

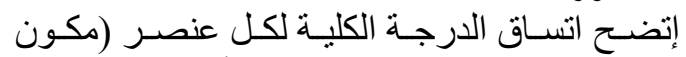

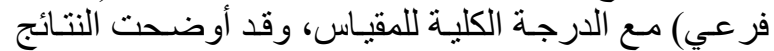

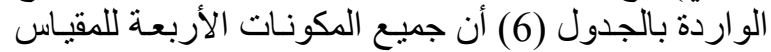

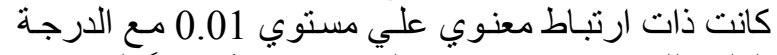

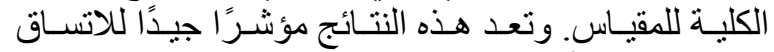
الداخلي لجميع أجز اء المقياس.

\section{5يفية إستخدام المقياس}

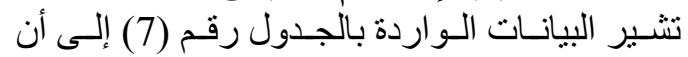

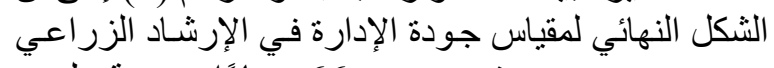

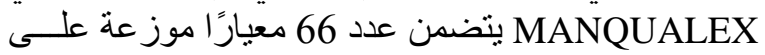

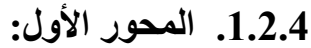

اتساق كل عبارة من عبار الات المقات المقياس (66 معيار)

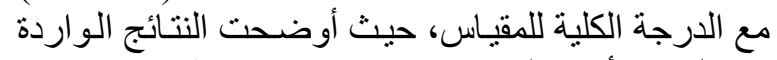

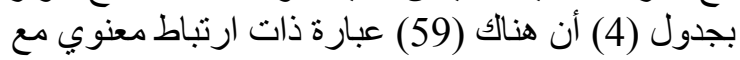

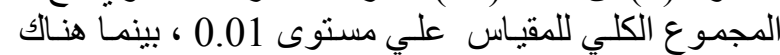

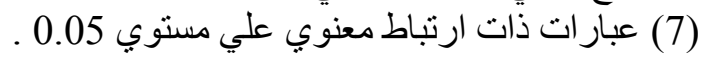

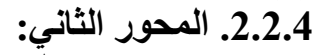

تبين اتسـاق كل عبارة مـع درجـة العنصر (المكون

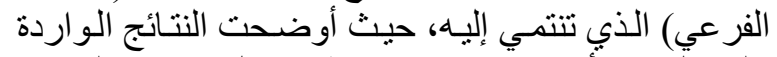

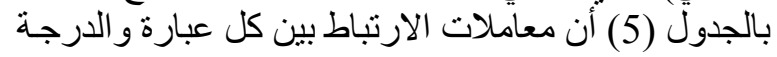

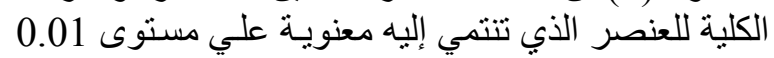

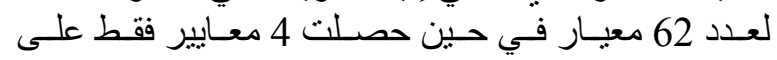

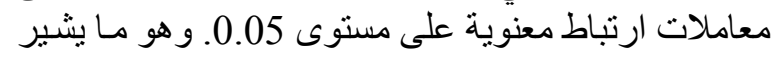


جدول (4): معاملات ارتباط وحدات المقياس مع الدرجة الكلية لمعايير جودة الإدارة في الجهاز الارشادي ومتوسطاتها

\begin{tabular}{|c|c|c|c|c|c|c|c|c|c|c|c|}
\hline \multicolumn{12}{|c|}{ الحسابية وانحرافتها المعيارية. } \\
\hline المعياري & الحستوسي & الارتباط & العبارات & المعياري & الحستابي & معامل الارتباط & العبارتات & الالحيراف & الحستوبي & الارتباط & العبارتيب \\
\hline 1.33 & 4.05 & 0.766 & 3 & 0.89 & 4.32 & 0.845 & 2 & 0.74 & 4.55 & ${ }^{*} 0.607$ & 1 \\
\hline 1.03 & 4.27 & 0.439 & 6 & 1.11 & 4.23 & 0.702 & 5 & 1.31 & 4.00 & 0.702 & 4 \\
\hline 1.38 & 4.00 & 0.832 & 9 & 1.62 & 3.82 & 0.502 & 8 & 1.11 & 4.23 & 0.845 & 7 \\
\hline 0.89 & 4.32 & 0.622 & 12 & 0.95 & 4.05 & 0.544 & 11 & 1.37 & 3.59 & 0.605 & 10 \\
\hline 0.72 & 4.32 & 0.753 & 15 & 0.59 & 41 & 0.605 & 14 & 0.84 & 4.32 & 0.875 & 13 \\
\hline 0.91 & 4.18 & 0.703 & 18 & 1.25 & 3.86 & 0.853 & 17 & 0.75 & 4.23 & 0.612 & 16 \\
\hline 0.91 & 4.45 & 0.645 & 21 & 0.48 & 4.68 & 0.754 & 20 & 0.99 & 4.14 & 0.672 & 19 \\
\hline 0.59 & 4.59 & 0.583 & 24 & 0.46 & 4.73 & 0.472 & 23 & 0.74 & 4.55 & 0.770 & 22 \\
\hline 1.13 & 4.14 & 0.626 & 27 & 1.02 & 4.23 & 0.853 & 26 & 0.74 & 4.45 & 0.743 & 25 \\
\hline 1.00 & 4.36 & 0.493 & 30 & 0.67 & 50 & 0.844 & 29 & 0.97 & 4.23 & 0.450 & 28 \\
\hline 0.99 & 32 & 0.887 & 33 & 0.80 & 4.55 & F 0.880 & 32 & 0.96 & 4.18 & 0.910 & 31 \\
\hline 0.83 & 4.27 & 0.866 & 36 & 0.80 & 4.45 & 0.733 & 35 & 1.00 & 4.36 & 0.725 & 34 \\
\hline 0.72 & 4.32 & 0.712 & 39 & 0.67 & 4.41 & 0.512 & 38 & 0.51 & 4.50 & 0.666 & 37 \\
\hline 0.80 & 4.41 & 0.558 & 42 & 0.79 & 4.36 & 0.703 & 41 & 1.23 & 4.00 & 0.853 & 40 \\
\hline 0.74 & 4.55 & 0.770 & 45 & 0.91 & 4.45 & 0.645 & 44 & 0.48 & 4.68 & 0.754 & 43 \\
\hline 0.67 & 4.59 & 0.925 & 48 & 0.59 & 4.59 & 0.857 & 47 & 0.46 & 4.73 & 0.551 & 46 \\
\hline 0.86 & & 0.9 & 51 & 0.74 & & 0.649 & 50 & 0.96 & 4.45 & 0.635 & 49 \\
\hline 0.97 & 4.23 & 0.734 & 54 & 0.84 & 4.32 & 0.607 & 53 & 0.51 & 4.45 & 0.549 & 52 \\
\hline 0.77 & 4.14 & 0.741 & 57 & 0.72 & 4.32 & 0.644 & 56 & 0.60 & 4.45 & 0.695 & 55 \\
\hline 0.58 & 4.64 & 0.530 & 60 & 1.01 & 4.18 & 0.541 & 59 & 1.15 & 4.09 & 0.645 & 58 \\
\hline 0.96 & 4.45 & 0.551 & 63 & 1.01 & 4.41 & 0.936 & 62 & 0.59 & 4.59 & 0.857 & 61 \\
\hline 0.51 & 4.45 & 0.649 & 66 & 0.86 & 4.45 & 0.766 & 65 & 0.74 & 4.55 & 0.845 & 64 \\
\hline
\end{tabular}

المصدر: نتائج التحليل الإحصائي * معنوي عند مستوى 0.05 ** معنوي عند مستوى 0.0106

جدول (5): معاملات ارتباط وحدات المكونات الفرعية النهائية لمعايير جودة الإدارة في الارشاد الزراعي مع الدرجة الكلية لهذه

\begin{tabular}{|c|c|c|c|c|c|c|c|c|}
\hline & & & & & & & \multicolumn{2}{|r|}{ المكونات الفرعية. } \\
\hline الارتباط & المعيار & الارتباط & المعيار & الارتباط معامل & المعيار & الارتباط معامل & المعيار & أبعاد المقياس \\
\hline 0.782 & 4 & 0.908 & 3 & 0.840 & 2 & ${ }^{*} 0.606$ & 1 & \\
\hline 0.724 & 8 & ${ }^{*} 0.890$ & 7 & ${ }^{*} 0.845$ & 6 & 0.890 & 5 & \\
\hline 0.840 & 12 & 0.480 & 11 & 0.632 & 10 & 0.454 & 9 & \\
\hline 0.673 & 16 & ${ }^{*} 0.630$ & 15 & 0.606 & 14 & 0.853 & 13 & البعد الاول: التركيز على \\
\hline 0.751 & 20 & 0.699 & 19 & *0.779 & 18 & 0.702 & 17 & \\
\hline 0.548 & 24 & 0.752 & 23 & 0.665 & 22 & *0.608 & 21 & \\
\hline$x x$ & $x x$ & $x x$ & $x x$ & $x x$ & $x x$ & 0.744 & 25 & \\
\hline${ }^{* * *} 0.749$ & 29 & * 0.737 & 28 & 0.825 & 27 & ${ }^{*} 0.801$ & 26 & \\
\hline 0.911 & 33 & 0.827 & 32 & 0.618 & 31 & 0.454 & 30 & البعات البالي: البد البدات البدات \\
\hline$x x$ & $x x$ & $x x$ & $x x$ & 0.882 & 35 & 0.916 & 34 & \\
\hline${ }^{* * *} 0.735$ & 39 & ${ }^{*} 0.771$ & 38 & 0.724 & 37 & ${ }^{*} 0.886$ & 36 & \\
\hline${ }^{* * *} 0.896$ & 43 & 0.567 & 42 & 0.557 & 41 & * 0.638 & 40 & \\
\hline 0.693 & 47 & 0.712 & 46 & *0.819 & 45 & 0.752 & 44 & البعلد الثالث: \\
\hline 0.944 & 51 & 0.861 & 50 & *0.594 & 49 & *0.910 & 48 & \\
\hline$x \times$ & $x \times$ & $x \times$ & $x \times$ & $x \times$ & $x \times$ & 0.562 & 52 & \\
\hline${ }^{* * *} 0.861$ & 56 & 0.717 & 55 & 0.879 & 54 & 0.802 & 53 & \\
\hline${ }^{* * *} 0.541$ & 60 & 0.868 & 59 & 0.859 & 58 & 0.833 & 57 & البعد الرابع: إتخاذ القرارات \\
\hline 0.711 & 64 & 0.607 & 63 & 0.520 & 62 & 0.706 & 61 & إعتمادًا على الأدلة \\
\hline$x x$ & $x x$ & $x x$ & $x x$ & 0.695 & 66 & 0.824 & 65 & \\
\hline
\end{tabular}

المصدر : عينة الاراسة * مغنوي علي مستوي 0.050 .010 .010 
جدول (6): معاملات الارتباط البينية والمتوسطات الحسابية والاتحر افات المعيارية للمكونات الفرعية الأربعة لمقياس جودة

\begin{tabular}{|c|c|c|c|c|c|}
\hline المقياس الكلي & (4) & (3) & (2) & (1) & أبعاد المقياس \\
\hline & & & & 1 & 1. التركيز على المستهدفين \\
\hline & & & 1 & * 0.879 & 2. التحسين المستمر للعمليات \\
\hline & & 1 & 0.889 & 0.936 & 3. ت تمكين وتدريب العاملين \\
\hline & 1 & 0.879 & 0.677 & * 0.822 & 4. إتخاذ القرارات إعتمادًا على الأدلة \\
\hline 1 & * 0.891 & 0.980 & 0.907 & 0.979 & المقياس الكلي \\
\hline 291.0 & 61.27 & 75.77 & 43.32 & 110.64 & المتوسط الحسابي \\
\hline 40.17 & 8.50 & 9.19 & 7.13 & 17.48 & الانحراف المعياري \\
\hline
\end{tabular}

جدول (7) : بيانات أساسية لمقياس MANQUALEX في صورته النهائية.

\begin{tabular}{|c|c|c|c|c|c|c|c|}
\hline \multicolumn{3}{|c|}{ مدى فئات جودة الإدارة } & \multicolumn{2}{|c|}{ المدى النظري } & \multicolumn{2}{|c|}{ الصورة النهائية } & \multirow[b]{2}{*}{ أبعاد المقياس } \\
\hline جودة مرتفعة & متوسطة & منخفضة & الأفضصى الحد & الأدنى & $\%$ & المعايير & \\
\hline $125-93$ & $92-59$ & $58-25$ & 125 & 25 & 37.88 & 25 & 1. التركيز على المستهدفين \\
\hline $50-37$ & $36-24$ & $23-10$ & 50 & 10 & 15.15 & 10 & 2. التحسين المستمر للعمليات \\
\hline $85-63$ & $62-40$ & $39-17$ & 85 & 17 & 25.76 & 17 & 3. تمكين وتدريب العاملين بالجهاز الإرشادي \\
\hline $70-52$ & $51-33$ & $32-14$ & 70 & 14 & 21.21 & 14 & 4. إتخاذ القرار ات إعتمادًا على الأدلة \\
\hline $330-243$ & $241-154$ & $153-66$ & 330 & 66 & 100 & 66 & المقياس الكلي \\
\hline
\end{tabular}

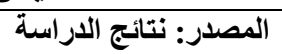

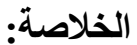

بناء على النتائج المتحصل عليها من الدر اسة الحالية

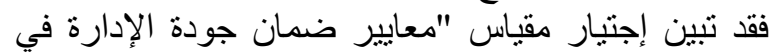

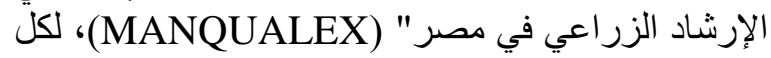

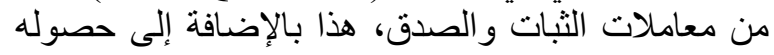

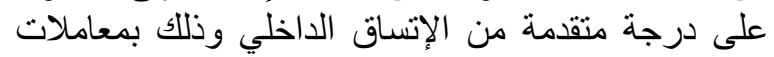

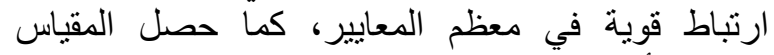

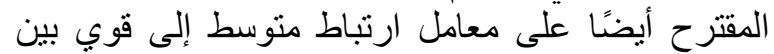

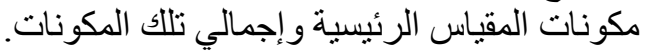

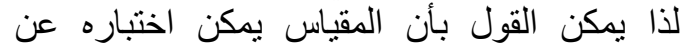
طريق التجريب، ووحدات المقياس قابلة للجمع، ويتضيكن الفيارن

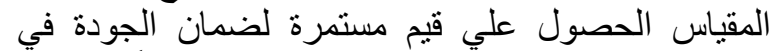

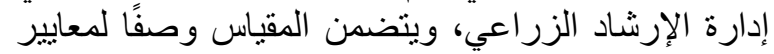

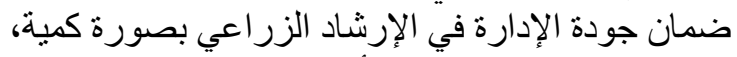

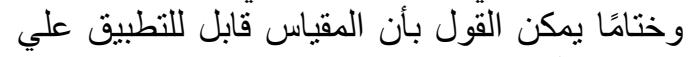

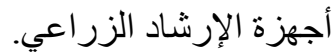
ويمكن إستخدام بنود المقياس في تحديد الوضع الإنع

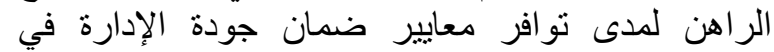
الإرشاد الزراعي حتى يمكن الوقوف عنى على الإمكانيات

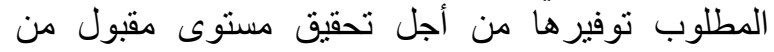
معايير ضمان جودة الإدارة لتكون اللبنة الثانية بعد معايير

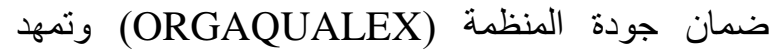
الطريق نحو صياغة معايير ضمان جودة الخدمة في الإرشاد الزراعي (SERVQUALEX).

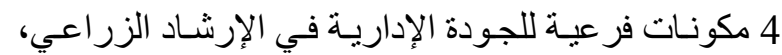

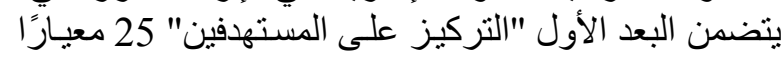

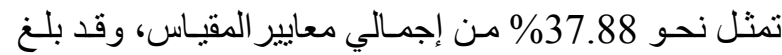

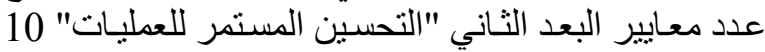

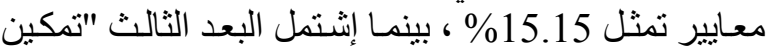

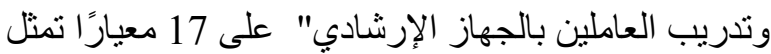

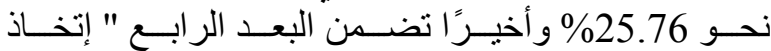

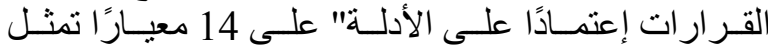

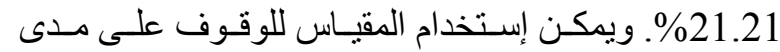

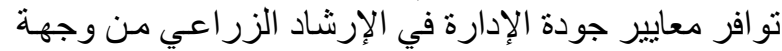

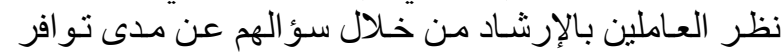

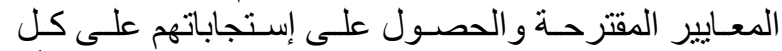

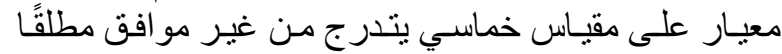

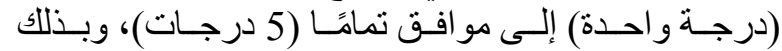

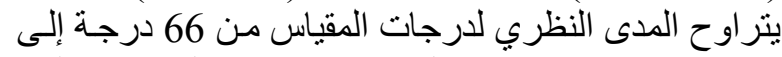

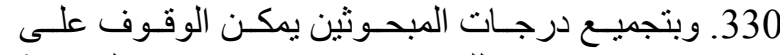

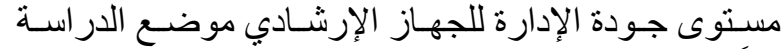

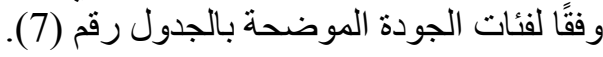

\section{6.المقياس في شكله النهائي}

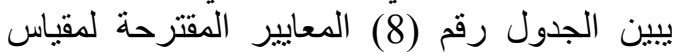

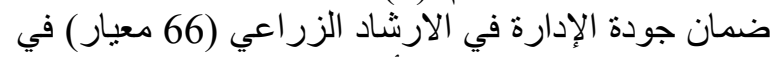
شكلها النهائي وموز الإدة فعة على أبعاد المقياس. 
جدول رقم (8): مقياس معايير ضمان جودة الإدارة في الإرشاد الزراعي MANQUALEX في صورته النهائية

\begin{tabular}{|c|c|}
\hline البعد الأول: التركيز على المستهدفين & مسلسل \\
\hline ملائمة الخدمة المقدمة لظروف المستهدفين الاجتماعية و الاقتصادية & 1 \\
\hline رضا المستهدفين عن الخدمات المقدمة لهم & 2 \\
\hline الإستماع لأفكار أصحاب المصلحة لتطوير الخدمات الإرشادية & 3 \\
\hline إستخدام الطرق الإرشادية التي يفضلها المستهدفين & 4 \\
\hline الإهتمام بالاستماع لأفكار العاملين بالأقسام المختلفة لتطوير الأقسام الأخرى & 5 \\
\hline رضا العاملين بالأقسام عن أنشطة الأقسام الأخرى & 6 \\
\hline مشاركة المستهدفين في تحديد شكل ونوع ووقت تقديم الخدمات الإرشادية & 7 \\
\hline ملائمة محتوي البر امج الإرشادية لفئات المستهدفين & 8 \\
\hline إعلام المستهدفين مسبقًا بالخدمات الإرشادية التي ستقدم لهم ومو اعيد تقديمها & 9 \\
\hline تقديم الخدمات الإرشادية حسب الوقت المحدد و المعلن للمستهدفين & 10 \\
\hline المعاملة الحسنة من العاملين بالإرشاد للمستهدفين & 11 \\
\hline تقديم الخدمات الإرشادية بطرق متعددة & 12 \\
\hline تقديم الخدمات الإرشادية بطرق جديدة & 13 \\
\hline الإستجابة السريعة و الفقّالة لمشاكل و إستفسار ات المستهدفين & 14 \\
\hline رغبة العاملين بالإرشاد في خدمة المستهدفين بإستمر ار & 15 \\
\hline نو افر طرق واضحة لتقييم الخدمات الإرشادية & 16 \\
\hline الإعتماد على تقييم المستهدفين لتحسين الخذمات الإرشادية & 17 \\
\hline إمتلاك العاملين بالإرشاد لمهار ات التعامل مع المشاكل الطارئة & 18 \\
\hline تحري الصدق و الدقة في تقديم الخدمات الإرشادية & 19 \\
\hline تقديم الخدمات الإرشادية بناء على حاجات و أولويات المستهدفين & 20 \\
\hline شعور المستهدفين بالثقة و الأمان عند التعامل مع الجهاز الإرشادي & 21 \\
\hline كفاية ساعات العمل لخدمة جميع المستهدفين & 22 \\
\hline إعلام المستهوفين بالمعلومات المتعلقة بنطوير الخدمات الإرشادية & 23 \\
\hline إعتماد مناهج تقديم الخدمة الإرشادية على الطلب و التركيز على العنصر البشري & 24 \\
\hline مدى إهتمام الإرشاد الزر اعي بمهام تثقيفية غير زر اعية حول البيئة و السكان و الأمن الغذائي ... الخ & 25 \\
\hline البعد الثاني: التحسين المستمر للعمليات & \\
\hline وضوح التوصيف الوظيفي لمهام العاملين بالجهاز الإرشادي & 26 \\
\hline تقسيم العمل بين العاملين بالإرشاد على كافة المستويات التنظيمية & 27 \\
\hline وجود خطة زمنية محددة لتنفيذ المهام & 28 \\
\hline الاستفادة من تكنولوجيا الحاسب و الإنترنت في العمليات الإدارية (ميكنة الجهاز الإرشادي) & 29 \\
\hline الاستفادة من تكنولو جيا الاتصال و المعلومات في تقديم الخدمات الإرشادية & 30 \\
\hline إهتمام العاملين بالإرشاد بالتطوير المستمر للخدمات الإرشادية & 31 \\
\hline التطوير المستمر للخدمات الإرشادية في جميع المستويات & 32 \\
\hline الإهتمام بتقديم خدمات إرشادية جيدة بصرف النظر عن عددها & 33 \\
\hline الشعور الدائم للعاملين بالإرشاد بالتقصير وضرورة تقديم الأفضل & 34 \\
\hline تعريف التطوير المستمر في صورة أرقام للتكلفة والوقت والآداء & 35 \\
\hline
\end{tabular}


تابع جدول (8): إستكمال

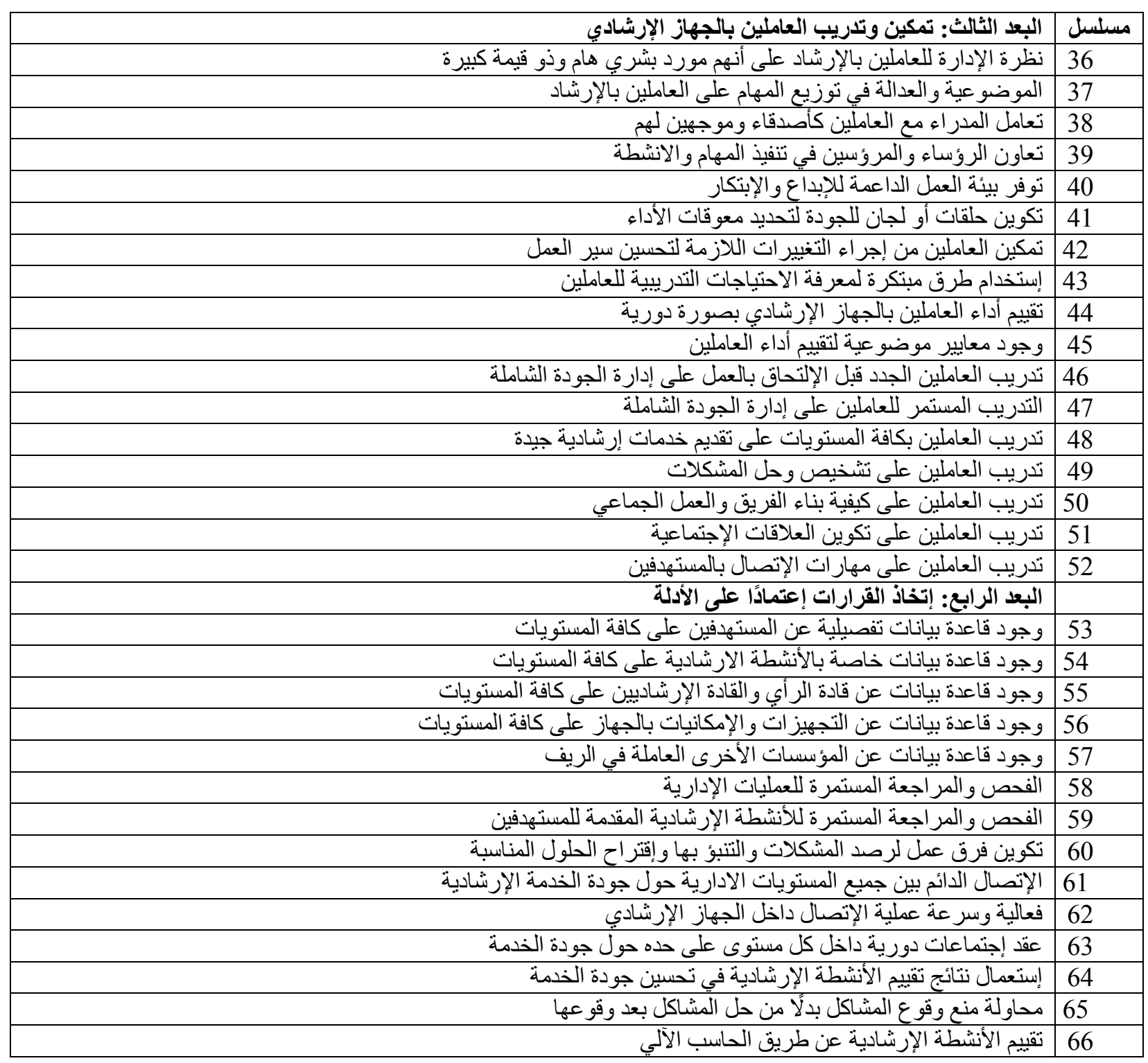

و العلوم الإجتماعية ، مجلد 8، العدد 4 ، ص ص

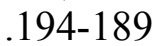

ريحان، إبراهيم ومجدى على يحيى (2005). مقاييس

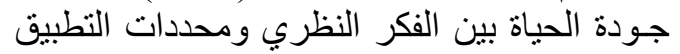
العملي: در اسة حالة علي قرية نوى الفي - مركز شبين الفين القناطر - بمحافظة القليوبية. المجلة المية المصرية

للعلوم التطبيقية، مجلد 20، العدد 7. زين الدين، فريد عبد الفتاح (1996). الفئه المنهج العملي

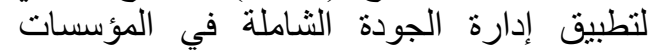
العربية، دار الكتب للنشر، القاهرة.

سليم ، حسن مختار حسين (2009). إدارة الجودة الثاملة الطئة

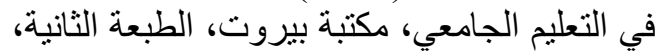

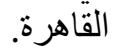

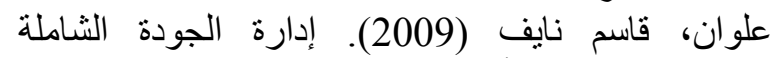
ومنطلبات الأيزو 2000-2001)، للنشر والتوزيع، الطبعة الثانية، عمان، الأردن.

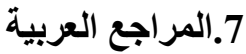

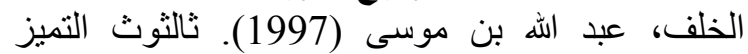

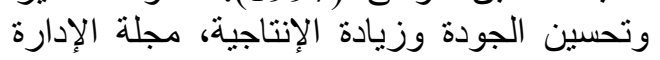
العامة، معهد الإدر اة العامة ، الرياض الإنتانة ، مجلد 37 ،

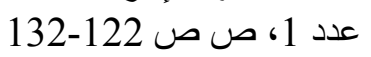

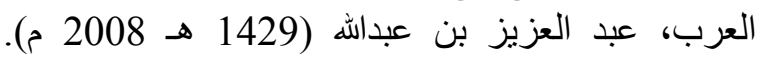
الجودة الثاملة في إدارة المستشفيات: دراسة

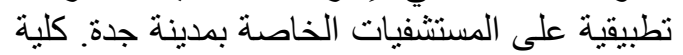

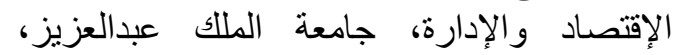
المملكة العربية السعودية الإدة جالمعة

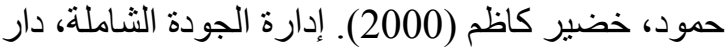
المسيرة للنشر و التوزيع، الطبعة الأولى، عمان.

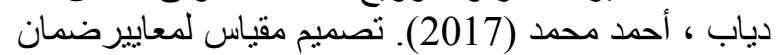

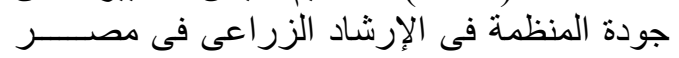
(ORGAQUALEX) 


\section{REFERENCES}

Abdel-Ghany M. M. and Diab A. M. (2013). Reforming agricultural extension in Egypt from the viewpoint of central level extension employees. Arab Univ. J. Agric. Sci., 21(2): 143-154.

Anandajayasekeram P., Puskur R., Workneh S. and Hoekstra D. (2008). Concepts and practices in agricultural extension in developing countries: A source book. IFPRI (International Food Policy Research Institute), Washington, DC, USA, and International Livestock Research Institute (ILRI), Nairobi, Kenya.

Charatsari Ch., Papadaki-Klavdianou A. and Michailidis A. (2009). Comparing Information in Organic Farming, Conventional Agriculture and Integrated Crop Management. In Chiara Paffarini and Fabio Maria Santucci (2009). Theory and practice of advisory work in a time of turbulences, $19^{\text {th }}$ European Seminar on Extension Education, Italy, pp 308-313.

Farooq M.S., Akhtar M. S. , Zia Ullah S. and Memon R.A. (2007). Application of total quality management in education. J. Quality and Technol. Manag. III(I1): 8797.

ISO (2015). Quality management principles. International Organization for Standardization (iso.org), Geneva, Switzerland.
Jain S. K. and Gupta G. (2004). Measuring Service Quality: SERVQUAL vs. SERVPERF Scales. VIKALPA, 29(2); 25-37.

Karbasioun M., Biemans H., Mulder M. (2008). Farmers' Learning Strategies in the province of Esfahan. The Journal of Agric. Edu. Exten. 14(4): 307-318

Kenyon G. N. and Sen K.C. (2015). The Perception of Quality: Mapping Product and Service Quality to Consumer Perceptions. Springer-Verlag London.

Qamar M. K. (2005). Modernizing National Agricultural Extension Systems: A practical Guide for Policy-makers of Developing Countries. Food and Agriculture Organization of the United Nations, Rome.

Schaafsma S.C.T. and Mulder M. (2009). The Meaning of Entrepreneurship Education for Extension Services. In: Chiara Paffarini and Fabio Maria Santucci (2009). Theory and practice of advisory work in a time of turbulences, $19^{\text {th }}$ European Seminar on Extension Education, Italy, pp 203-208.

Swanson B.E. (2009). Changing extension paradigms within a rapidly changing global economy. In: Chiara Paffarini and Fabio Maria Santucci (eds). Theory and practice of advisory work in a time of turbulences, $19^{\text {th }}$ European Seminar on Extension Education, Italy, pp 113-117. 